JOURNAL OF RESEARCH of the National Bureau of Standards-A. Physics and Chemistry Vol. 69A, No. 1, January-February 1965

\title{
Preparation of a Carbonate-Free Complex Calcium Aluminate
}

\author{
H. A. Berman
}

(September 29, 1964)

\begin{abstract}
Compounds found in portland cement are difficult to prepare completely free of carbon dioxide. The difficulty is further intensified in the case of calcium aluminate monosulfate by the instability of the compound in the course of its precipitation from solution and the consequent need for preparing it within a limited time. The compound has been prepared in a large quantity, free of carbon dioxide, by using a closed-system precipitation and filtration assembly, in which rapid movement of the reagent solutions and mother liquor is achieved by the manipulation of trapped pockets of previously prepared $\mathrm{CO}_{2}$-free air. The precipitate is conditioned and packaged in a glove box in which a $\mathrm{CO}_{2}$-free atmosphere is maintained. Techniques are described in detail.
\end{abstract}

\section{Introduction}

The study of the compounds present in dry and hydrated portland cement is complicated by the ease with which all these materials absorb, adsorb, and react with carbon dioxide. Failure to account for this sensitivity has led many workers to erroneous identification of some of these compounds or to inaccurate determinations of their properties. Notable among these errors has been the postulation of the existence of hexagonal tricalcium aluminate hexahydrate, shown recently to be a mixture of dicalcium aluminate and tetracalcium aluminate carbonate hydrates [1]. ${ }^{1}$

Among the $\mathrm{CO}_{2}$-sensitive compounds either found in or related to hydrated portland cement are the calcium aluminate complex salts of the general formula $3 \mathrm{CaO} \cdot \mathrm{Al}_{2} \mathrm{O}_{3} \cdot q \mathrm{CaX} \cdot n \mathrm{H}_{2} \mathrm{O}$, where $q=1$ or 3 and $n=10$ to 12 or 30 to 33 , respectively, and $X$ is a divalent ion or two units of a monovalent ion. The two sulfates in this group, $3 \mathrm{CaO} \cdot \mathrm{Al}_{2} \mathrm{O}_{3} \cdot \mathrm{CaSO}_{4}$. $12 \mathrm{H}_{2} \mathrm{O}$ and $3 \mathrm{CaO} \cdot \mathrm{Al}_{2} \mathrm{O}_{3} \cdot 3 \mathrm{CaSO}_{4} \cdot 32 \mathrm{H}_{2} \mathrm{O}$, are readily transformed in the presence of $\mathrm{CO}_{2}$ to hydrated alumina and $\mathrm{CaCO}_{3}$, and often to the corresponding calcium aluminate monocarbonate, $3 \mathrm{CaO} \cdot \mathrm{Al}_{2} \mathrm{O}_{3}$. $\mathrm{CaCO}_{3} \cdot 11 \mathrm{H}_{2} \mathrm{O}[2]$. (In the process, the monosulfate is changed to the trisulfate or free $\mathrm{CaSO}_{4}$ may appear.) The monocarbonate and its corresponding' tricarbonate, $3 \mathrm{CaO} \cdot \mathrm{Al}_{2} \mathrm{O}_{3} \cdot 3 \mathrm{CaCO}_{3} \cdot 30 \mathrm{H}_{2} \mathrm{O}$, are similarly converted by additional $\mathrm{CO}_{2}$ to $\mathrm{CaCO}_{3}$ and hydrated alumina [3].

In the course of a thermochemical program designed to determine the heat of formation of the complex calcium aluminate salts, attempts have been made to prepare these salts as free of carbonate

1 Figures in brackets indicate the literature references at the end of this paper. impurity as possible. Samples of calcium aluminate monosulfate have been prepared with analyzed $\mathrm{CO}_{2}$ contents from 0.09 to 0.45 percent by weight [2]; samples of calcium aluminate trisulfate, from 0.24 to 2.1 percent [4]. In general, the monosulfate and those trisulfates lowest in $\mathrm{CO}_{2}$ were made in closed systems with precautions taken to exclude carbon dioxide.

However, the ubiquity of $\mathrm{CO}_{2}$ has defeated attempts to prepare these materials entirely $\mathrm{CO}_{2}$-free. Up to the present work, no successful preparation entirely $\mathrm{CO}_{2}$-free has reached the attention of the author. It is difficult to handle these materials in the complete absence of room air when grinding and mixing the dried powder or during such operations as transfer from filters to conditioning desiccators and thence to storage bottles. It is almost impossible to maintain completely tight vacuum desiccators in an ordinary laboratory. The experiences of many investigators have been similar $[5,6]$.

An additional problem in the precipitation of calcium aluminate monosulfate is the necessity for bringing together large quantities of $\mathrm{Ca}(\mathrm{OH})_{2}$ and $\mathrm{Al}_{2}\left(\mathrm{SO}_{4}\right)_{3}$ in a short time. The monosulfate is transformed to the trisulfate if the precipitate stands too long in contact with the mother liquor. The larger the molar ratio of $\mathrm{Ca}(\mathrm{OH})_{2}$ to $\mathrm{Al}_{2}\left(\mathrm{SO}_{4}\right)_{3}$ added (up to about 20:1), the longer the time available before this conversion begins to take place, but, at the same time, the lower the yield of precipitate. A 50-liter batch produces only about $30 \mathrm{~g}$ of the dried monosulfate. This problem has been met [2] by filling the reaction bottle several times, mixing, and drawing off the supernatant liquor between fillings. A large quantity of precipitate builds up and is all digested with the same mother liquor after the last mixing operation. 
The National Bureau of Standards has been participating in a group effort to study the properties of portland cement constituents and improve methods of identification. As part of the effort, this laboratory was asked to prepare reference samples of the two calcium aluminate sulfates in large quantity (about $100 \mathrm{~g}$ ) for distribution to the participating laboratories.

A sample of the highest purity, as free of $\mathrm{CO}_{2}$ as possible, was desired. The results obtained for two lots of calcium aluminate monosulfate are given first, followed by a description of the apparatus and techniques employed. The procedure used is then given in sufficient detail to illustrate the techniques.

\section{Results}

Two samples of calcium aluminate monosulfate, $3 \mathrm{CaO} \cdot \mathrm{Al}_{2} \mathrm{O}_{3} \cdot \mathrm{CaSO}_{4} \cdot 12 \mathrm{H}_{2} \mathrm{O}$, were prepared. Lot 1, produced with a yield of $40 \mathrm{~g}$, had a $\mathrm{CO}_{2}$ content (by conventional methods of calculation from sample and blank determinations) of 0.015 percent, with a negligible standard error in precision. The estimated uncertainty in accuracy is $0.03,{ }^{2}$ inasmuch as the $\mathrm{CO}_{2}$ determinations were made at the limit of detectability of this compound. Lot 2, containing $79 \mathrm{~g}$, had 0.005 percent $\mathrm{CO}_{2}$, with a standard error estimate of \pm 0.005 percent in precision, by the same conventional calculation, with the same uncertainty in accuracy.

The values obtained in the sample and blank $\mathrm{CO}_{2}$ determinations are shown in table 1.

The figure for accuracy is based on the fact that the largest value for a blank determination for each sample is equal to or greater than the largest value for a sample determination. The upper limit of uncertainty in accuracy is taken as the largest weight increase found for a sample determination without making a subtraction for the blank.

It is probable that the materials contained no $\mathrm{CO}_{2}$ at all.

The analyses of the samples and calculated compound compositions are shown in table 2 .

TaBle 1. Carbon dioxide determirations

\begin{tabular}{|c|c|c|c|c|}
\hline \multirow{2}{*}{$\frac{\text { Lot }}{\text { Determination }}$} & \multicolumn{2}{|c|}{1} & \multicolumn{2}{|c|}{2} \\
\hline & A & B & $\mathrm{A}$ & B \\
\hline $\begin{array}{l}\text { Weight increase in absorption tube: } \\
\text { Blank, prior to sample determina- } \\
\text { tion } \\
\text { Sample determination } \\
\text { Blank, after sample determina- } \\
\text { tion } \\
\text { Sample minus blank average } \\
\text { Weight of sample } \\
\text { Calculated percent " } \mathrm{CO}_{2}, \mathrm{~g}_{-} \text {in } \\
\text { sample a }\end{array}$ & $\begin{array}{c}0.0003 \\
.0003 \\
.0000 \\
.00015 \\
1.0147 \\
0.015\end{array}$ & $\begin{array}{r}0.0002 \\
.0003 \\
.0000 \\
.0002 \\
1.4164 \\
0.014\end{array}$ & $\begin{array}{r}0.0005 \\
-.0001 \\
.0002 \\
\text { ь. } 0000 \\
.8734\end{array}$ & $\begin{array}{r}0.0002 \\
.0003 \\
.0001 \\
.00015 \\
1.5204\end{array}$ \\
\hline
\end{tabular}

a See discussion in text. The uncertainty of the determination is 0.03 percent, or twice the calculated value for Lot 1.

b Negative values ignored.

${ }^{2}$ The uncertainty in accuracy is given as a range rather than a standard deviation.
TABLE 2. Analysis of the samples

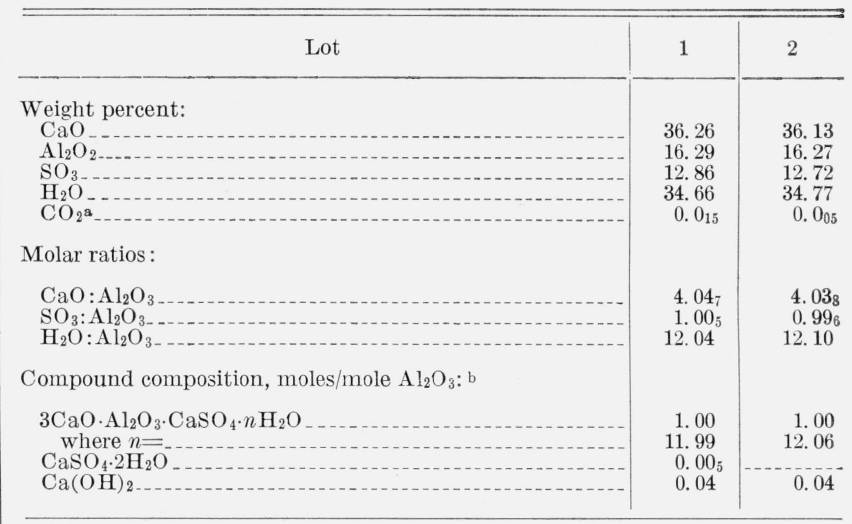

a See table 1 for actual determinations of $\mathrm{CO}_{2}$, and see text for discussion. The uncertainty of the determination is 0.03 percent, or twice the calculated value for Lot 1 .

b Calculations of compound composition are based on the procedure described in the appendix to reference [4].

\section{Apparatus and Techniques, Materials, and Procedures}

The general steps in the procedure were as follows. The samples were prepared by precipitation from essentially $\mathrm{CO}_{2}$-free solutions of $\mathrm{Ca}(\mathrm{OH})_{2}$ and $\mathrm{Al}_{2}\left(\mathrm{SO}_{4}\right)_{3}$ in the closed-system assembly shown schematically in figure 1, and in simplified form in figure 2. The precipitate was filtered in a closed system shown in figure 1 . The filter funnel containing the precipitate was transferred (with exit and entrance tubes closed off) to the glove box shown schematically in figure 3 . There the precipitate was placed in a desiccator, for conditioning at 33 percent relative humidity, until its loss on ignition was constant. It was then ground inside the glove box, mixed in a sealed jar, and packaged inside the box.

The equipment and techniques used in each of these steps are first described generally. In succeeding sections, enough of the detailed procedure is described to illustrate these techniques.

\subsection{Apparatus and Techniques}

\section{a. Precipitation}

The precipitation system shown in figure 1 was designed to move large quantities of liquid into and out of the reaction bottle in a short time. It consists of four storage bottles for $0.02 \mathrm{M} \mathrm{Ca}(\mathrm{OH})_{2}$, labeled $\mathrm{A}_{1}, \mathrm{~A}_{2}, \mathrm{~A}_{3}$, and $\mathrm{A}_{4}$; a bottle containin g approximately $4 N$ NaOH, labeled $\mathrm{A}_{0}$; a bottle for the reaction, $\mathrm{B}$; and an overflow bottle, C. These are nominal 13-gal polyethylene containers capable of holding 58 liters. Bottle D is a 2.5-liter commercial reagent acid bottle, containing $0.1 M \mathrm{Al}_{2}\left(\mathrm{SO}_{4}\right)_{3}$ solution; and bottle $\mathrm{E}$ is a long, narrow container graduated to measure the quantity of $\mathrm{Al}_{2}\left(\mathrm{SO}_{4}\right)_{3}$ solution fed to bottle $\mathrm{B}$.

Bottle B is closed with a rubber stopper furnished with the ser en tubes shown in figure 1, and also with a ground-glass bearing which serves as a guide for a ground-glass stirring shaft $86 \mathrm{~cm}$ long. When lubricated with a grease furnished by the manufac- 
turer, the shaft closure is air-tight, but the shaft is free to turn. This type of stirrer was used instead of a magnetic stirrer, which could not effectively stir 50 liters of solution when activated through the thick bottom of the polyethylene bottle.

To obtain rapid flow, glass tubing $9 \mathrm{~mm}$ o.d. was used for the liquid lines, whereas $7-\mathrm{mm}$ tubing was adequate for the air lines. For steps in which the speed of transferring a liquid was most important, three or four lines were used in parallel. Since stopcock bores are small in cross section, pinchcocks with screw-thread closure on tygon tubing were used instead for all the one-way valves.

Figure 2 is a simplified drawing of the essential parts of the precipitation system, from which the principles involved are more readily evident than they are from figure 1 . Rapid transfer of liquid must be accomplished with rapid movement of $\mathrm{CO}_{2}$-free air. Since it is impossible to remove all the $\mathrm{CO}_{2}$ by absorption from an air stream moving at high velocity, a slow stream of air is passed through a $\mathrm{CO}_{2}$-absorption train, and the air is stored in bottles $\mathrm{B}$ and $\mathrm{C}$ prior to the mixing operation. $\mathrm{Ca}(\mathrm{OH})_{2}$ is then siphoned from one of the A bottles into bottle B, while the air in $\mathrm{B}$ rapidly moves into $\mathrm{A}$ to displace the $\mathrm{Ca}(\mathrm{OH})_{2}$. Similarly, in drawing off the supernatant liquor from $\mathrm{B}$ to $\mathrm{C}$, air in $\mathrm{C}$ rapidly moves into $\mathrm{B}$, providing at the same time a source of displacement air for the next transfer of $\mathrm{Ca}(\mathrm{OH})_{2}$ from an A bottle to $\mathrm{B}$.

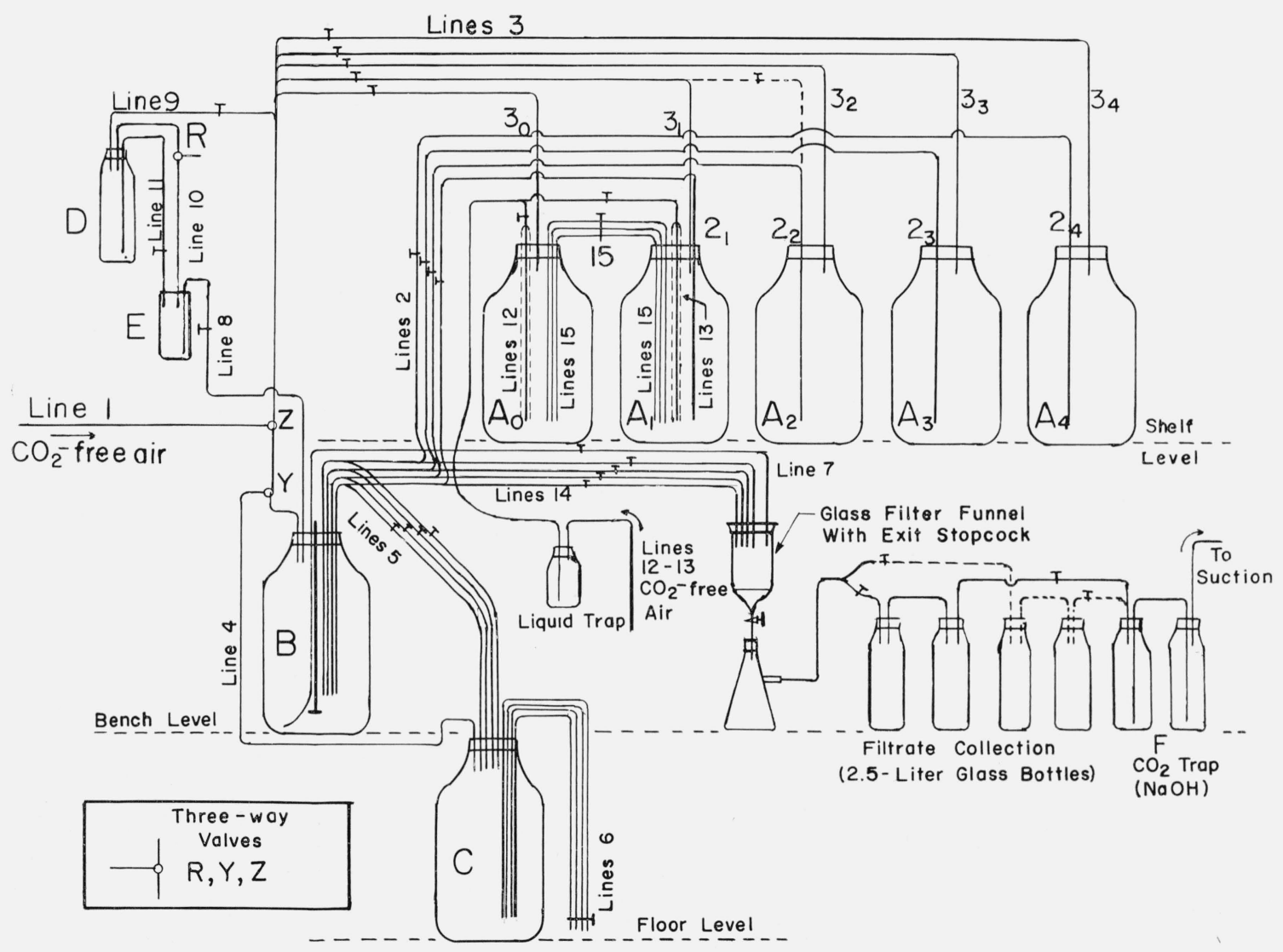

Figure 1. Closed system for precipitation and filtration.

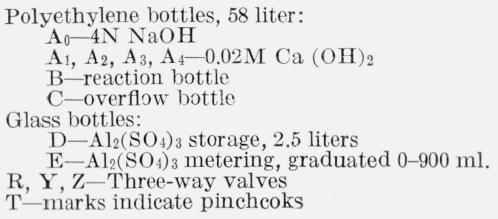




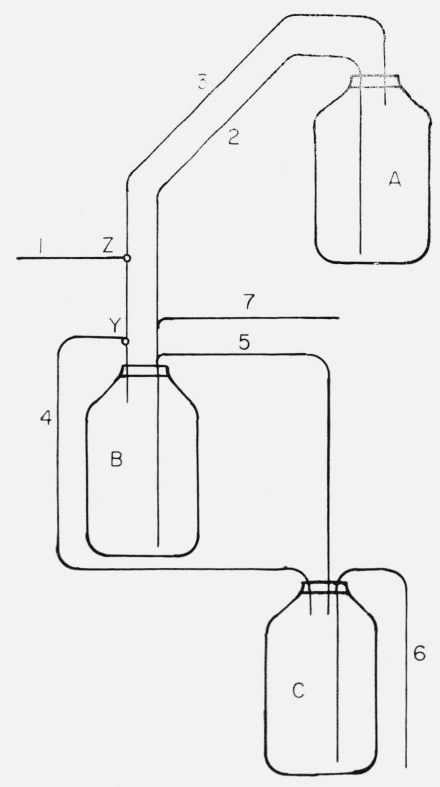

Figure 2. Simplified representation of a portion of figure 1.

A. Calcium hydroxide storage bottle.

B. Reaction bottle.

Y, Z. Three-way valves.

\section{b. Conditioning}

The glove box shown in figure 3 consists of a main chamber $A$, and a 30-liter airlock $B$ which can be evacuated to $1 \mathrm{~cm} \mathrm{Hg}$ or better. Two $\mathrm{CO}_{2}$-absorption trains, similar to those described in the section immediately following, provide air for the main chamber, airlock, and conditioning chambers F inside the box. The train on the left serves the main chamber directly and provides continuous positive pressure in the chamber. The box had been provided with an air outlet with $\mathrm{NaOH}$ traps, but the positive pressure was found to be accommodated by movement of the rubber gloves and by some residual leakage. The train on the right feeds air to two sets of air-storage bottles $\mathrm{C}$ (shown in fig. 3 only as two bottles) with a total capacity of 120 liters (45 liters of air and 75 of saturated $\mathrm{Ca}(\mathrm{OH})_{2}$ solution with excess solid $\mathrm{Ca}(\mathrm{OH})_{2}$ ). The bottles are so arranged that when air is fed to one set, the $\mathrm{Ca}(\mathrm{OH})_{2}$ solution is displaced to the other set, in turn displacing the air in the second set to the particular chamber which is being purged. The object of this procedure is to fill the chamber rapidly from a stored supply of $\mathrm{CO}_{2}$-free air (from set $\mathrm{C}_{2}$, for example, with pincheock $\mathrm{D}_{1}$ open, $\mathrm{D}_{2}$ closed). In the process, air passing rapidly through the train enters set $\mathrm{C}_{1}$ in an amount equal to the air leaving $\mathrm{C}_{2}$. Only partially purified by the train, the air in $\mathrm{C}_{1}$ is allowed to stand in contact with the $\mathrm{Ca}(\mathrm{OH})_{2}$ solution overnight to complete the removal of $\mathrm{CO}_{2}$. It is then available for another rapid purge the next day, when the flow through the bottles, but not through the system, is reversed by closing pinchcock

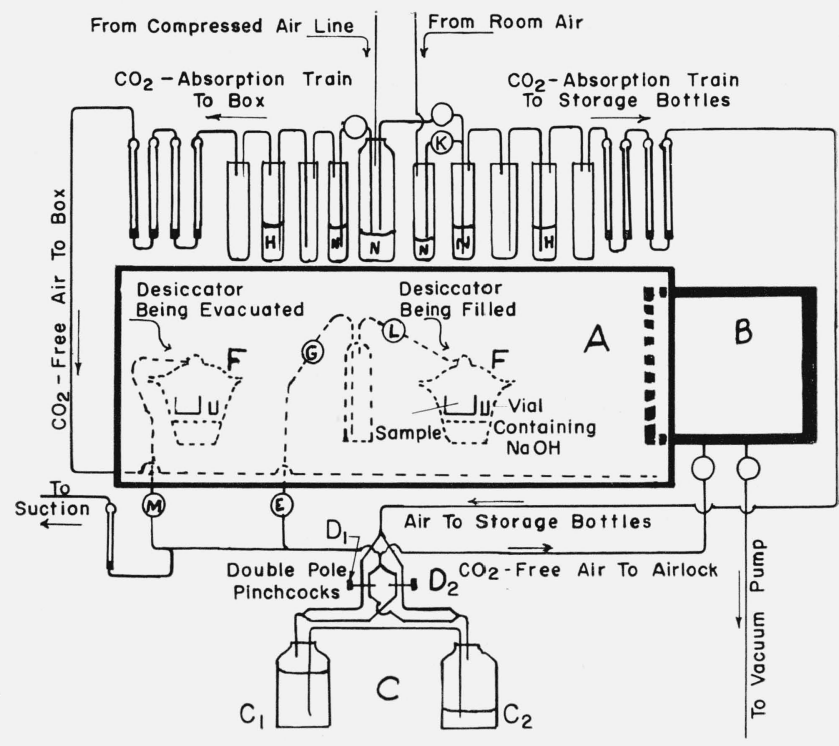

FIgURE 3. Glove box and air storage system.

$$
\begin{aligned}
& \text { A. Main chamber. } \\
& \text { B. Airlock. } \\
& \text { C. CO } \mathrm{O}_{2} \text {-free air storage bottles. } \\
& \text { D. "Double-pole, double-throw" pincheock sys- } \\
& \text { tem for reversing flow in air storage bottle } \\
& \text { C. When one pincheock is open, the other } \\
& \text { is closed; each cock controls two lines si- } \\
& \text { multaneously. } \\
& \text { E, G, K, L, M. Pincheocks. } \\
& \text { F. Conditioning desiccators. } \\
& \text { H. Sulfuric acid. } \\
& \text { N. Sodium hydroxide solution. }
\end{aligned}
$$

$\mathrm{D}_{1}$ and opening $\mathrm{D}_{2}$, the pinchcock system acting in a manner analogous to that of a double-pole, doublethrow reversing switch.

The conditioning chambers $\mathrm{F}$ are vacuum desiccators containing both $\mathrm{MgCl}_{2} \cdot 6 \mathrm{H}_{2} \mathrm{O}$ for maintaining 33 percent relative humidity and small vials with a few pellets of $\mathrm{NaOH}$ to remove any traces of $\mathrm{CO}_{2}$ from the desiccator air. ${ }^{3}$ The desiccator and contents are purged several times outside the glove box by evacuating to about $2 \mathrm{~cm} \mathrm{Hg}$ pressure with an aspirator and refilling with $\mathrm{CO}_{2}$-free air passed through saturated $\mathrm{MgCl}_{2}$ solution. The desiccator is then evacuated and placed in the airlock. The airlock is evacuated, refilled with $\mathrm{CO}_{2}$-free air from the storage bottles (air entering the right-hand train from the room through valve $\mathrm{K}$ ). The airlock is then opened to the main chamber and the desiccator transferred thereto. Desiccators are prepared in this manner for later use. When it is time to place the precipitated and filtered material into a desiccator, the latter is refilled with $\mathrm{CO}_{2}$-free air by opening valves $\mathrm{D}, \mathrm{E}, \mathrm{G}$, and $\mathrm{L}$, the air passing through a bottle of saturated $\mathrm{MgCl}_{2}$ solution before entering the desiccator. After the material is placed in the desiccator, it is evacuated by an aspirator through valve $\mathrm{M}$.

${ }^{3}$ A solution of $11.4 \mathrm{~N} \mathrm{NaOH}$ was first used because its water-vapor pressure corresponds to 33 percent relative humidity, but the $\mathrm{NaOH}$ solution picked up water from the precipitates faster than it surrendered it to the $\mathrm{MgCl}_{2}$ solution and overflowed into the latter solution. The small quantity of solid $\mathrm{NaOH}$ is not enough to disturb the water-vapor equilibrium in the desiccator. 


\subsection{Materials}

\section{a. $\mathrm{CO}_{2}$-Free Air}

The $\mathrm{CO}_{2}$-free air used during the precipitation (figs. 1 and 2) and during the conditioning (fig. 3) was furnished by several trains, only one of which is illustrated (fig. 3). Compressed air from a 40-psi line is passed successively through: (1) a pressurereducing valve (0-25 psi outlet); (2) a needle valve; (3) five test tubes or gas-washing bottles, of which the first, third, and fifth are traps, the second contains $4 N \mathrm{NaOH}$, and the fourth contains concentrated $\mathrm{H}_{2} \mathrm{SO}_{4}$; (4) and finally through a series of four straight absorption bulbs, each of which contains ascarite, magnesium perchlorate, and indicating anhydrite. For independent, trouble-free operation, each $\mathrm{CO}_{2}$-free air train is provided with its own reducing and needle valve. The bulbs with solid absorbents last almost indefinitely if the $\mathrm{NaOH}$ and $\mathrm{H}_{2} \mathrm{SO}_{4}$ solutions are replenished often. The $\mathrm{NaOH}$ solution lasts longer if it is made from $\mathrm{CO}_{2}$-free water and $20 \mathrm{~N} \mathrm{NaOH}$ which has been filtered or decanted from its $\mathrm{Na}_{2} \mathrm{CO}_{3}$ impurity.

\section{b. Aluminum Sulfate (Approximately 0.1 $M$ )}

The apparatus is shown in figure 4. All containers are filled with $\mathrm{CO}_{2}$-free air either by evacuation and refilling, or by filling them with $\mathrm{CO}_{2}$-free water and displacing the water with the air. A 1-lb bottle of reagent $\mathrm{Al}_{2}\left(\mathrm{SO}_{4}\right)_{3} \cdot 18 \mathrm{H}_{2} \mathrm{O}$ (not purged before being placed in the assembly) is fitted with a 3-hole stopper and tubes as shown in B, figure 4. It is placed in a water bath $\mathrm{C}$ over a hot plate $\mathrm{F}$. The bottle is evacuated, then boiling distilled $\mathrm{H}_{2} \mathrm{O}$ is admitted to it from flask A. After a few minutes of digestion, the hot solution is transferred by pressure to fritted glass filter funnel $\mathrm{E}$ and the filtrate eventually collected in the 2.5-liter storage bottle $\mathrm{D}$, later to be connected to the assembly in figure 1 . The reagent bottle $\mathrm{B}$ is again evacuated, more hot $\mathrm{H}_{2} \mathrm{O}$ is admitted, and the process is continued until all the solid has been dissolved. The filtrate is thoroughly mixed and divided roughly equally among three bottles (D, figs. 1 and 4 ). The transfer is made with $\mathrm{CO}_{2}$-free air. The divided filtrates are cooled in $\mathrm{CO}_{2}$-free air, and $\mathrm{CO}_{2}$-free $\mathrm{H}_{2} \mathrm{O}$ is added to fill the $\mathrm{D}$ bottles. The contents are mixed, and, under $\mathrm{CO}_{2}$-free air pressure, a sample is removed from each bottle for analysis to determine the $\mathrm{Al}_{2} \mathrm{O}_{3}$ and $\mathrm{SO}_{3}$ concentrations, to be used later in proportioning the precipitation mixture and in calculating material balances.

\section{c. Calcium Hydroxide}

Eleven liters of distilled $\mathrm{H}_{2} \mathrm{O}$ is boiled in a 12-liter flask about $15 \mathrm{~min}$. and allowed to cool to room temperature with the flask stoppered but connected to the outlet of a $\mathrm{CO}_{2}$-free air line. About $18 \mathrm{~g}$ of $\mathrm{CaO}$, prepared by igniting low-alkali reagent $\mathrm{CaCO}_{3}$ at $1000{ }^{\circ} \mathrm{C}$ to constant weight, is added to the cooled $\mathrm{H}_{2} \mathrm{O}$ while the flask is momentarily unstoppered.

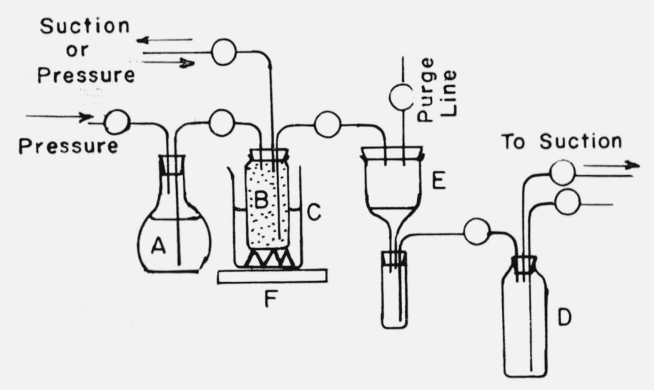

FIgURE 4. Closed system for preparing aluminum sulfate solution.

A. Boiling $\mathrm{CO}_{2}$-free $\mathrm{H}_{2} \mathrm{O}$.

B. Aluminum sulfate in original reagent bottle.

C. Hot water bath.

D. Aluminum sulfate storage bottle.

E. Filter funnel.

F. Hot plate.

The mixture is stirred with a magnetic stirrer several hours. Before the system shown in figure 1 is completely assembled, ${ }^{4}$ the four A bottles are filled with $\mathrm{Ca}(\mathrm{OH})_{2}$ solution in the following manner. An exit delivery tube from the 12-liter flask (not shown in the figures) is connected to one of the $\mathrm{A}$ bottles through the appropriate line 2. With the stirrer still on, the $\mathrm{Ca}(\mathrm{OH})_{2}$ solution is transferred to the A bottle under pressure of $\mathrm{CO}_{2}$-free air. The air in the A bottle is displaced through lines 3 and 1 (line 1 disconnected from the $\mathrm{CO}_{2}$-free air line). Successive batches are made in this manner until bottles $A_{1}$ to $\mathrm{A}_{4}$ are filled. The undissolved $\mathrm{Ca}(\mathrm{OH})_{2}$ in these bottles serves to keep the solution $\mathrm{CO}_{2}$-free; any $\mathrm{CaCO}_{3}$ that forms settles to the bottom and is not carried over into the reaction bottle.

With the system of figure 1 still only partially assembled, any $\mathrm{Ca}(\mathrm{OH})_{2}$ remaining in lines 14 is flushed out with $\mathrm{CO}_{2}$-free water, added from a flask in the same manner as the $\mathrm{Ca}(\mathrm{OH})_{2}$ was added, and ejected from the open end of the flexible tubing which normally connects line 2 to bottle $B$ when the apparatus is fully assembled.

\subsection{Procedures}

\section{a. Precipitation}

The procedure is described here only in sufficient detail to illustrate the principles involved, and, for this purpose, reference is first made to the simplified drawing in figure 2.

Bottles $\mathrm{B}$ and $\mathrm{C}$ are filled with hot $\mathrm{CO}_{2}$-free water. The water is slowly displaced with $\mathrm{CO}_{2}$-free air, a process which takes about two days per bottle. The bottles are again filled with hot $\mathrm{CO}_{2}$-free water and once more with $\mathrm{CO}_{2}$-free air. The water is added to bottle B through line 7 from a 12-liter flask under $\mathrm{CO}_{2}$-free air pressure, the room air in the bottles being displaced through lines 3 and 1 with valves $\mathrm{Y}$ and $\mathrm{Z}$ in the appropriate positions, and line 1

${ }^{4}$ At this time, bottles $\mathrm{B}$ and $\mathrm{C}$, the filtration system, and the $\mathrm{A}$ bottles, are three separate closed systems. 
disconnected from the $\mathrm{CO}_{2}$-free air line but connected to the $\mathrm{NaOH}$ trap of the filtration system $\mathrm{F}$ at a convenient point (fig. 1). Water is added to bottle $\mathrm{C}$ through line 6 , displacing the air through lines 4 , 3 , and 1. Air is added to the bottles in the reverse directions with line 1 connected to the $\mathrm{CO}_{2}$-free air line.

After bottles B and $\mathrm{C}$ have been purged in this manner, the entire precipitation and filtration assembly of figure 1 may be connected together, so that the precipitation may be started.

At the start of the working day, bottle $\mathrm{B}$ is filled with $\mathrm{Ca}(\mathrm{OH})_{2}$ from bottle $\mathrm{A}_{1}$ (fig. 1) or A (fig. 2) by the following two-step procedure. Line 2 is filled with $\mathrm{Ca}(\mathrm{OH})_{2}$ solution by allowing $\mathrm{CO}_{2}$-free air to pass through lines 1 and 3 into bottle $A$, thereby forcing $\mathrm{Ca}(\mathrm{OH})_{2}$ solution to fill line 2 . Valve $\mathrm{Y}$ is set to allow the air from B to pass through line 4 into bottle C. This step takes only a moment and therefore requires no venting of bottle C. As soon as line 2 is full of liquid, the hydrostatic head in line 2 permits the flow to continue without air pressure from line 1. Valves $\mathrm{Y}$ and $\mathrm{Z}$ are then turned to close off lines 1 and 4 and open line 3 to bottle B. Air in bottle $\mathrm{B}$ is now displaced to bottle $\mathrm{A}$ as the $\mathrm{Ca}(\mathrm{OH})_{2}$ in bottle A fills bottle B.

Bottle E (fig. 1) is then filled with $\mathrm{Al}_{2}\left(\mathrm{SO}_{4}\right)_{3}$ solution from bottle $\mathrm{D}$ by a similar two-step procedure, in which line 11 is first filled with the solution under air pressure through lines 1,3 , and 9 . When line 11 is full, the air pressure is no longer needed, and the $\mathrm{Al}_{2}\left(\mathrm{SO}_{4}\right)_{3}$ solution continues to flow into $\mathrm{E}$, the air being displaced from $\mathrm{E}$ to $\mathrm{D}$ through line 10. When $\mathrm{E}$ is full of solution, the flow continues up line 10 until the level in line 10 is the same as the level in D. Since line 10 is only $1.8 \mathrm{~mm}$ i.d., only a negligible quantity of $\mathrm{Al}_{2}\left(\mathrm{SO}_{4}\right)_{3}$ solution enters line 10 .

The stirrer in bottle B is turned on, line 11 is closed off, and air pressure to $\mathrm{E}$ via lines 1, 3, 9, and 10 forces $\mathrm{Al}_{2}\left(\mathrm{SO}_{4}\right)_{3}$ solution to flow from $\mathrm{E}$ to $\mathrm{B}$ through line 8. Flow continues until the desired quantity of $\mathrm{Al}_{2}\left(\mathrm{SO}_{4}\right)_{3}$ solution, measured in bottle $\mathrm{E}$, has been added; line 8 is then shut off.

Stirring is continued as long as necessary $(6 \mathrm{~min}$ for the calcium aluminate monosulfate), and the precipitate is then allowed to settle (about $10 \mathrm{~min}$ ).

As described in the introduction, it is now necessary to remove the supernatant liquor and replace it with a second batch of reagent solutions. The liquor is transferred to bottle $\mathrm{C}$ by a two-step technique identical to that used to fill B with solution from $\mathrm{A}$, the air in $\mathrm{C}$ replacing the liquor from $\mathrm{B}$. Thus, the $\mathrm{CO}_{2}$-free air originally trapped in $\mathrm{B}$ and $\mathrm{C}$ is used to help transfer these liquids rapidly without depending on slow movement of air through a $\mathrm{CO}_{2}$ removal train. To insure rapid flow of the liquid, line 5 actually consists of four parallel lines, as shown in figure 1.

The second, third, and fourth batches of reagent solutions are added in a similar manner, except that rapid transfer of $\mathrm{Ca}(\mathrm{OH})_{2}$ in each addition is more critical because the first precipitate is already in contact with the mother liquor. Rapid flow is achieved by drawing from three $\mathrm{Ca}(\mathrm{OH})_{2}$ bottles simultaneously $\left(A_{2}, A_{3}\right.$, and $A_{4}$ in fig. 1). The technique, in principle, is to cause air to flow rapidly into bottle $\mathrm{A}_{0}$, bubbling in the process through the $\mathrm{NaOH}$ solution in that bottle, displacing the $\mathrm{NaOH}$ into bottle $A_{1}$. The $\mathrm{CO}_{2}$-free air already in bottle $A_{1}$ is allowed to flow into $A_{2}, A_{3}$, and $A_{4}$, pushing the $\mathrm{Ca}(\mathrm{OH})_{2}$ solution in these bottles into $\mathrm{B}$. The air in $\mathrm{B}$ is displaced into $\mathrm{C}$, where it in turn forces the spent liquor in $\mathrm{C}$ into the room through line 6 . When bottle $\mathrm{B}$ contains the desired quantity of $\mathrm{Ca}(\mathrm{OH})_{2}$, the flow is stopped, and $\mathrm{Al}_{2}\left(\mathrm{SO}_{4}\right)_{3}$ solution is added as for the first batch.

The arrangement makes it possible to complete a four-batch precipitation of calcium aluminate monosulfate in $5 \mathrm{hr}$. This time period allows for $6 \mathrm{~min}$ of stirring and $10 \mathrm{~min}$ of settling after each of the first three additions, and $10 \mathrm{~min}$ of stirring and $20 \mathrm{~min}$ of settling before the filtration. The filtration requires two more hours. At a $\mathrm{Ca}(\mathrm{OH})_{2} / \mathrm{Al}_{2}\left(\mathrm{SO}_{4}\right)_{3}$ molar ratio of 20 , this total period of $7 \mathrm{hr}$ is within the limit for preparation of monosulfate without any conversion to trisulfate. The first addition of $\mathrm{Ca}(\mathrm{OH})_{2}$ has not been included in this time because reaction does not start until the $\mathrm{Al}_{2}\left(\mathrm{SO}_{4}\right)_{3}$ has been first added.

\section{b. Filtration}

On the day prior to the precipitation, the filter funnel is filled with $\mathrm{CO}_{2}$-free water through line 7 and vented through line 14 , with the exit stopcock of the funnel closed and both lines temporarily disconnected from bottle B. $\mathrm{CO}_{2}$-free air is introduced through line 7 and the water removed from the funnel by suction with the stopcock open. The funnel is purged several times in this manner; then, with air in the funnel, the stopcock is closed and the filtrate flask disconnected and emptied of its water. The apparatus is then reassembled as in figure 1.

After the final addition of $\mathrm{Ca}(\mathrm{OH})_{2}$ and $\mathrm{Al}_{2}\left(\mathrm{SO}_{4}\right)_{3}$, and a final stirring period of $10 \mathrm{~min}$ and a settling period of $20 \mathrm{~min}$ (in the particular case of preparing calcium aluminate monosulfate), the filtration is started. Suction is turned on in the suction line shown in figure 1, the exit stopcock of the filter funnel is opened, and clear liquid is first drawn rapidly from bottle B through lines 14 into the filter funnel. The liquid in bottle $\mathrm{B}$ is displaced by stored $\mathrm{CO}_{2}$-free air from bottle $A_{2}$, which is in turn replenished by fast-flowing air that has bubbled rapidly through the $\mathrm{NaOH}$ solution in bottle $A_{0}$. When the liquid level in bottle B approaches the bottom, the stirrer is turned on, and the necessary pinchcocks are adjusted to allow the slurry to flow through line 7 , which reaches to the bottom of bottle $B$. The precipitate then collects in the filter funnel. The filtrate collection bottles are so arranged that when two are full they may be disconnected from the system, their contents discarded, and the empty bottles returned to the system; meanwhile, the filtrate has been collecting in the other two filtrate collection bottles. 


\section{c. Conditioning}

When the filtration is completed, the stopcock of the filter funnel is closed and the suction end of the trap F (fig. 1) in the filtrate collection system is disconnected from the suction line, restoring atmospheric pressure to the system. The entrance tubes to the filter funnel are closed off by pinchcocks and disconnected from lines 7 and 14. An absorption bulb containing ascarite is attached to one of these entrance tubes, the pincheock opened and the funneltube assembly is placed in the airlock of the glove box. The airlock is evacuated and refilled with $\mathrm{CO}_{2}$ free air from the storage bottles as described above. The inner door is then opened and the assembly transferred to the main chamber. A conditioning desiccator in the main chamber is filled with $\mathrm{CO}_{2}$-free air (via $\mathrm{MgCl}_{2}$ solution) and the precipitate is transferred from the filter funnel to a suitable container and placed inside the desiccator. It is kept there until its loss on ignition is constant, being moved to other desiccators as the solid $\mathrm{MgCl}_{2} \cdot 6 \mathrm{H}_{2} \mathrm{O}$ is exhausted. The time required for conditioning is usually about two months. To obtain a sample for loss-on-ignition determination, a platinum crucible is ignited and weighed, then transferred inside a desiccator through the airlock into the box. A sample of the precipitate is placed in the crucible, which is then returned inside the desiccator to the room.

\section{d. Further Handling}

When the loss on ignition is constant, the sample is removed from the conditioning desiccator and ground inside the glove box with an agate mortar and pestle. It is then transferred to a jar which has been purged, evacuated, transferred to the glove box, and refilled with conditioned air in the same manner as the desiccators. The jar is closed, sealed with plastic tape, placed inside a polyethylene bag containing ascarite, and removed through the airlock to the room. The contents of the jar are mixed several days on a rotating wheel. The jar is returned to the glove box, removed from the polyethylene bag, and stored inside a conditioning desiccator. A sample for chemical analysis is placed in a weighing bottle and removed from the glove box by the same technique used to obtain a loss-on-ignition sample, as described in the preceding section.

After chemical analysis has been completed, the preparation is packaged in glass vials inside the glove box. The cap of the vial is taped to provide a seal and the vials are protected from the atmosphere in the following manner (shown in fig. 5): A length of glass tubing is sealed at one end. Freshly ignited $\mathrm{CaO}$ is placed in the sealed end and covered with glass wool. The glass tube is transferred to the glove box and a taped glass vial is inserted with the cap toward the sealed end. A plug of glass wool, a

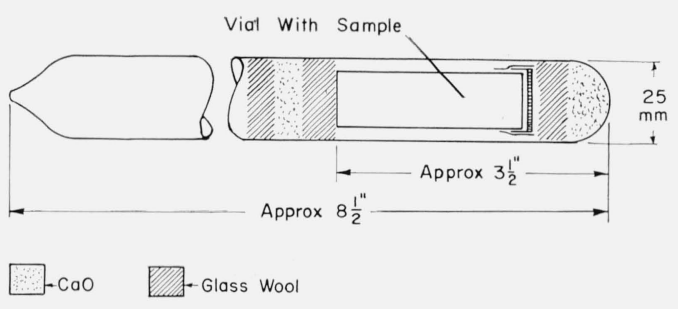

Figure 5. Packaging container.

layer of $\mathrm{CaO}$, and another plug of glass wool are then inserted. The assembly is removed from the glove box and the open end of the tube is sealed as rapidly as possible, leaving enough empty space to effect the seal without heating the sample.

\section{Summary and Conclusions}

Apparatus, techniques, and procedures have been described for the preparation of a complex calcium aluminate essentially free of carbonate impurity. The system has been used to prepare two lots of calcium aluminate monosulfate, $3 \mathrm{CaO} \cdot \mathrm{Al}_{2} \mathrm{O}_{3} \cdot \mathrm{CaSO}_{4}$. $12 \mathrm{H}_{2} \mathrm{O}$, and can be used in the form described, or with modifications, to prepare by precipitation other compounds that are sensitive to carbon dioxide. The system has also been used to make a large lot of calcium aluminate trisulfate, although in this case rapid liquid flow during the precipitation is not critical. As in the case of the monosulfate, it is particularly useful in those instances where the compound desired is stable only for a limited time in the presence of its mother liquor.

\section{References}

[1] R. Rabot and M. T. Mounier, On the existence of hexagonal tricalcium aluminate hydrate (in French) Revue des Matériaux de Construction et Travaux Publics 554, 449 (1961).

[2] H. A. Berman and E. S. Newman, Heat of formation of calcium aluminate monosulfate at $25^{\circ} \mathrm{C}$. J. Res. NBS 6rA (Phys. and Chem.), No. 1, 1 (1963).

[3] E. T. Carlson and H. A. Berman, Some observations on the calcium aluminate carbonate hydrates, J. Res. NBS 64A, (Phys. and Chem.), No. 4, 333 (1960).

[4] H. A. Berman and E. S. Newman, Heat of formation of calcium trisulfoaluminate at $25^{\circ} \mathrm{C}$, Proceedings of the Fourth International Symposium on the Chemistry of Cement (Washington, 1960); NBS Mono 43, pp. 247257.

[5] D. L. Kantro, L. E. Copeland, and E. R. Anderson, An X-ray diffraction investigation of hydrated portland cement pastes, ASTM Proceedings 60, 1020 (1960); Portland Cement Association Bulletin 128.

[6] P. Seligmann and N. R. Greening, Studies of early hydration reactions of portland cement by X-ray diffraction, in press.

(Paper 69A1-327) 